\title{
Evaluate Shielding Design of the Brachytherapy Unit by Using Monte Carlo Simulation Code
}

\author{
Ramin Jaberi' ${ }^{1}$ Mohammad Hadi Gholami2* ${ }^{*}$ Abdolazim Sedighi Pashaki², \\ Alireza Khoshghadam² \\ ${ }^{1}$ Cancer Institute of Tehran University of Medical Science, Tehran, Iran \\ ${ }^{2}$ Mahdieh Brachytherapy Charitable Center, Hamedan, Iran \\ Email: ${ }^{*}$ hadigholami2@gmail.com
}

Received 20 December 2014; accepted 20 June 2015; published 24 June 2015

Copyright (C) 2015 by authors and Scientific Research Publishing Inc.

This work is licensed under the Creative Commons Attribution International License (CC BY). http://creativecommons.org/licenses/by/4.0/

(c) (i) Open Access

\section{Abstract}

Shielding design is necessary for brachytherapy treatment room in order to protect the general public and employees. The main objective of this study was to investigate whether the protective unit of our Brachytherapy Centre provided adequate protection to the health and safety assessment of radiobiological impact. In this study, we estimated the effect of radiobiological protection from a single Ir-192 brachytherapy source in Brachytherapy center by using MCNP5 Monte Carlo measurements. The room was based on the design specifications for the HDR $192 \mathrm{Ir}$ treatment was modeled. The estimated dose rate range for HDR $192 \mathrm{Ir}$ and public buildings is $(0.45$ - 0.64): (micro sivert) $\mu \mathrm{Sv} / \mathrm{hour}$. Dose rates measured data for the current setup Brachytherapy HDR unit was approved and agreed quiet well with recommendation of International Atomic Energy Agency. The measured dose rate for public areas and controlled areas, compared with the reference value of $7.5 \mu \mathrm{Sv} / \mathrm{h}$ and $0.5 \mu \mathrm{Sv} / \mathrm{h}$ and concluded that we have enough shielding to the source but an over estimate with experimental measurements had been seen.

\section{Keywords}

Computer Codes and Modeling, Dose Equivalent, Effective Dose, Shielding, Monte Carlo Code System

\section{Introduction}

Monte Carlo N-Particle Transport Code (MCNP) is a software package for simulating nuclear processes. It is developed by Los Alamos National Laboratory since at least 1957 with several further major improvements [1].

\footnotetext{
${ }^{*}$ Corresponding author.
}

How to cite this paper: Jaberi, R., Gholami, M.H., Pashaki, A.S. and Khoshghadam, A. (2015) Evaluate Shielding Design of the Brachytherapy Unit by Using Monte Carlo Simulation Code. Journal of Modern Physics, 6, 902-911. 
It is distributed within the United States by the Radiation Safety Information Computational Center in Oak Ridge, TN and internationally by the Nuclear Energy Agency in Paris, France. It is used primarily for the simulation of nuclear processes, such as fission, but has the capability to simulate particle interactions involving neutrons, photons, and electrons. "Specific areas of application include, but are not limited to, radiation protection and dosimetry, radiation shielding, radiotherapy, medical physics, nuclear criticality safety, detector design and analysis, nuclear oil well logging, accelerator target design, fission and fusion reactor design, decontamination and decommissioning.” MCNPX (Monte Carlo N-Particle extended) is also developed at Los Alamos National Laboratory, and is capable of simulating particle interactions of 34 different types of particles (nucleons and ions) and 2000+ heavy ions at nearly all energies, including those simulated by MCNP [2]. Both codes can be used to judge whether or not nuclear systems are critical and to determine doses from sources, among other things. MCNP6 is a merger of MCNP5 and MCNPX [3]. The Monte Carlo code system MCNP is employed for the simulation. MCNP is a general purpose Monte Carlo radiation transport code which can simulate coupled neutron, and photo neutron transport in three dimensions through complex geometries is constructed as Boolean combinations of planes, spheres, cones and cylinders [4]. An energy cut off value of $1 \mathrm{KeV}$ is used to terminate tracking of photon and electron histories. MCNP requires the source for a particular problem to be specified in a userdefined input file. The source includes distributions of the positions, energy and angle of the starting particles. The cross section library containing data from the ENDF is included with the MCNP code that is utilized for the computations [4]. In this study, we use MCNP5 simulation code. This code is suitable for such shielding investigation because of an extensive library of cross sections for materials that are use for shielding, and then compare the experimental calculations with MCNP5 simulation in occupied areas and verify whether the shielding provides adequate protection for the staff and the public in its current operational state and make appropriate recommendations to address any radiological health and safety hazards identified. Brachytherapy is a technique by which sealed radioactive sources are introduced into the body and positioned near the tumor using appropriate applicator devices. This technique can deliver the desired dose to the tumor while avoiding damage to healthy tissues. To achieve the best possible treatment planning, it is very important to know as precisely as possible the dose distribution around not only the source but also the applicator [5]. Specially designed rooms should have sufficient shielding to limit the treatment radiation exposure dose received by other patients, nursing staff and members of the public in the surrounding areas [6]. There are several sources for use in brachytherapy such as 131 I, 60 co and 192 Ir [7]. Iridium-192 source at the Mahdieh Brachytherapy center is used for HDR (High Dose Rate) brachytherapy 192 Ir source use as after loading source with a half-life of 74 days, with a average gamma energy of about $0.38 \mathrm{MeV}$. Ir-192 with the activity between $2-12 \mathrm{Ci}$ (Curie is a unit of radioactivity and radioactive materials to be used to express the activity of the audit) can be used as HDR source in Brachytherapy. The brachytherapy design depends on treatment techniques, work load, activity of the source, nuclides and energy of source. In brachytherapy, room and wall shielding designs must be sufficient to reduce the primary and scattered radiation since the sources are unshielded in all directions. Brachytherapy treatment rooms should comply with both national and international regulations that deal with shielding requirement to render an installation safe from radiation protection point of view [8]. For public areas and controlled areas, radiation should be in reference value range of $0.75 \mu \mathrm{Sv} / \mathrm{h}$ and $0.5 \mu \mathrm{Sv} / \mathrm{h}$ [9]. The design should also take into the best simulation code to evaluate the shielding adequacy [10]. Mahdieh Brachytherapy had been invented in 2012 and had a treatment in 5 days a week.

\section{Materials and Methods}

The study was carried out at the Mahdieh hamadan brachytherapy center and using recommendation of IAEA47 (International Atomic Energy Agency protocol number 47) report for HDR brachytherapy units shielding [11]. First, we calculate the shielding of brachytherapy unit with the theoretical methods and formulas that have been described below.

\section{Gamma Exposure Rate Formula}

The exposure rate from a gamma point source can be approximated from the following expression

$$
X=\frac{A_{0} \Gamma}{r^{2}}
$$

where $X$ is the dose rate; $A$ is activity in $\mathrm{mCi}$; $\Gamma$ is the gamma factor; and $r$ distance in $\mathrm{cm}$ 
Monoenergetic $x$ or gamma rays collimated into a narrow beam are attenuated exponentially through a shield according to the following equation:

$$
I=I_{0} \mathrm{e}^{-\mu x}
$$

where $I$ is the intensity outside of a shield of thickness $x I_{0}$ is the unshielded intensity $\mu$ is the linear attenuation coefficient of the shielding material $x$ is the thickness of shielding material. The linear attenuation coefficient is the sum of the probabilities of interaction per unit path length by each of the three scattering and absorption processes - photoelectric effect, and pair production. Note that $\mu$ has dimensions of inverse length $(1 / \mathrm{cm})$. The reciprocal of $\mu$ is defined as the mean free path, which is the average distance the photon travels in an absorber before an interaction takes place.

Therefore, to confirm the calculations and validation of the calculation we used both experimental and Monte Carlo methods.

\section{Description of the Brachytherapy Facility}

The Mahdieh Radiotherapy Centre has a brachytherapy treatment rooms, a diagnostic Ct scan X-ray equipment and administrative setup. The brachytherapy treatment room shown in Figure 1 has a concrete shield of thickness $85 \mathrm{~cm}$. Flexitron machine facility at the center has a monitor located at the treatment planning room, office for monitoring the movements of the patient and communication system. Figure 1 shows the locations around the Ir-192 sources used for the study. The specific reason for choosing this points depends on the amount of traffic in that place, work place of technicians and nurses and commonalities between the X-ray machine. In this simulation, we must simulate source in height of 1meter from the ground and should be bare source. Locations $\mathrm{A}, \mathrm{B}, \mathrm{C}$ and $\mathrm{F}$ are the control area. B where the medical physicists with the Ct scan images plan the patient. Location A with a mdf and $0.4 \mathrm{~mm}$ lead door separates the entrance to the maze. Locations D, E are designated as the public areas and locations $\mathrm{F}$ is controlled area, schematic diagram to demonstrate the experiment process has been shown in Figure 2.

\section{Monte Carlo Simulation}

The brachytherapy treatment room of the Centre was modeled using the visual editor of the MCNPX code to the design specification of the facility. The concrete with a density of $2.35 \mathrm{~g} / \mathrm{cm}^{3}$ was used with material composition of ${ }^{1} \mathrm{H} 0.005558,{ }^{8} \mathrm{O} 0.498076,{ }^{11} \mathrm{Na} 0.017101,{ }^{12} \mathrm{Mg} \mathrm{0.002565},{ }^{13} \mathrm{Al} 0.045746{ }^{14} \mathrm{Si} 0.315092,{ }^{16} \mathrm{~S} 0.001283$, ${ }^{19} \mathrm{~K} 0.019239,{ }^{20} \mathrm{Ca} 0.082941,{ }^{26} \mathrm{Fe}_{54} 0.000707,{ }^{26} \mathrm{Fe}_{56} 0.01139{ }^{26} \mathrm{Fe}_{57} 0.000265,{ }^{26} \mathrm{Fe}_{58} 3.6 \times 10{ }^{-5}$. The entrance door of the facility is modeled as a mdf door with a density of $0.830 \mathrm{~g} / \mathrm{cm}^{3}$ [12]. $4 \mathrm{~mm}$ lead with density of

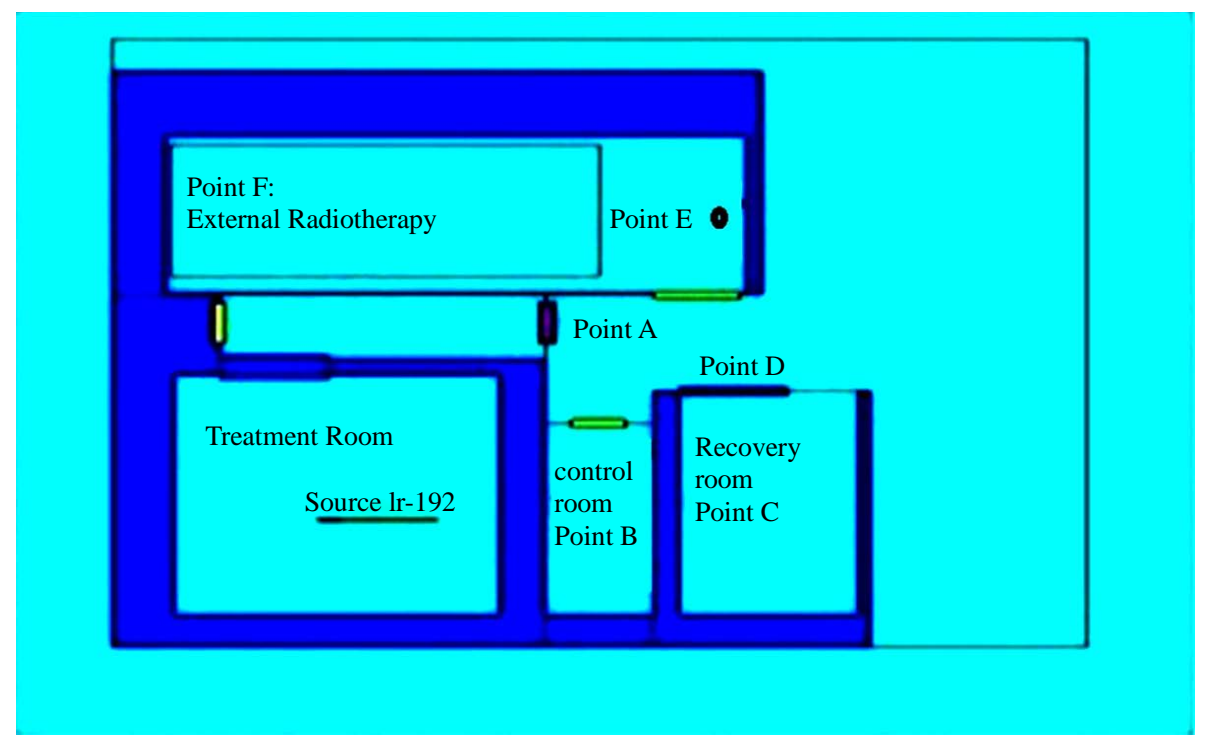

Figure 1. Brachytherapy site. 


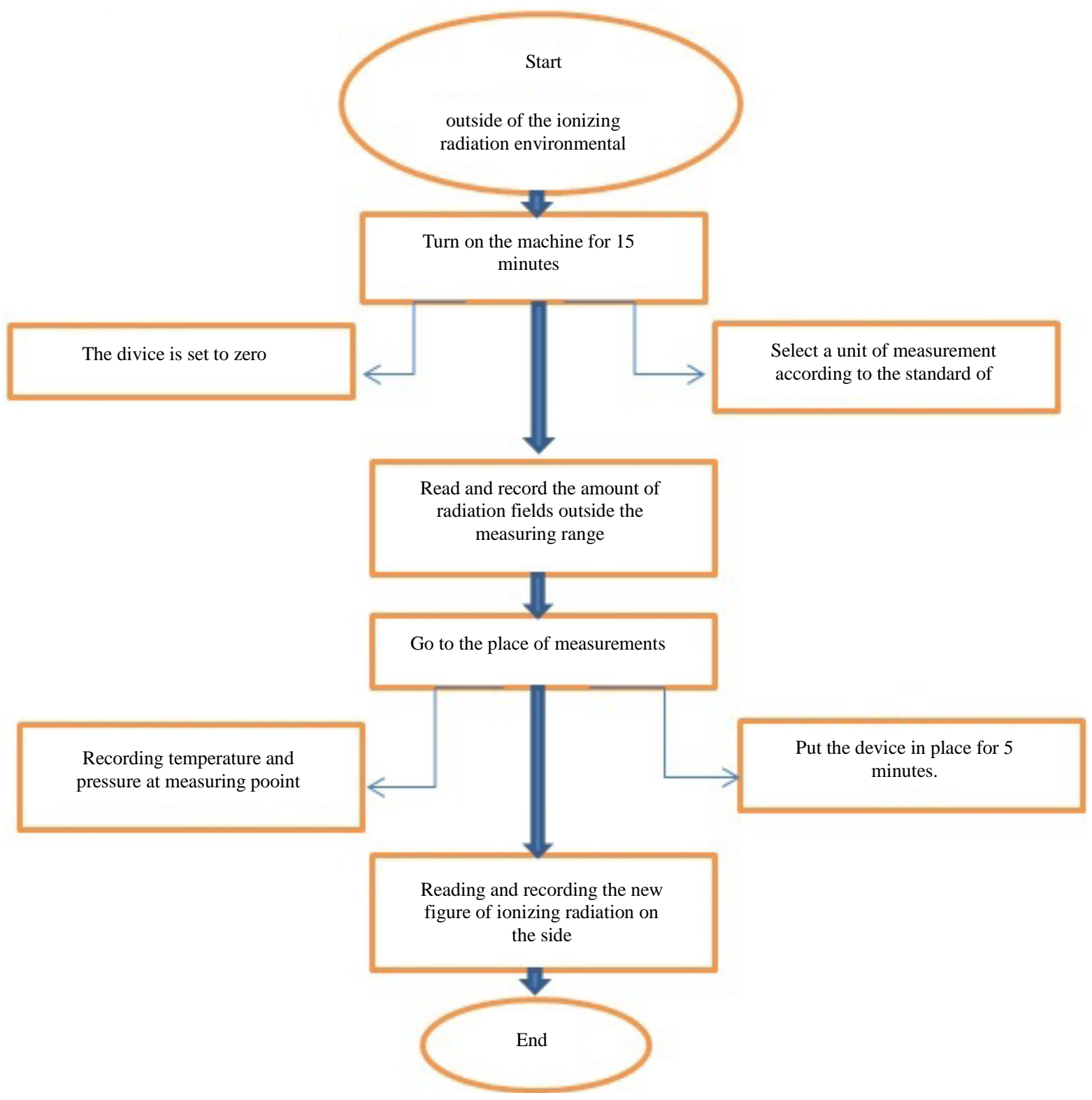

Figure 2. Schematic diagram to demonstrate the experiment process.

$11.35 \mathrm{~g} / \mathrm{cm}^{3}$ with material of ${ }^{82} \mathrm{~Pb}_{206} 0.242902,{ }^{82} \mathrm{~Pb}_{207} 0.223827,{ }^{82} \mathrm{~Pb}_{208} 0.53327$ use in mdf door [13] [14]. Brachytherapy sources; Ir-192 was modeled as Figure 3 with 5 activities of 11.5, 6.5, 5.7, 4.4 and 3.2 Ci.

It has been in existence till date using the decay equation:

$$
A=A_{0} \mathrm{e}^{-i \gamma t}
$$

where $A$ is the present activity, $A_{0}$ is the initial activity at a known time, $\gamma$ is the decay constant and $t$ is the time to the date of exposure. The Ir-192 HDR with activities (11.5, 6.1, 5.7, 4.4 and 3.2) Ci, was used for the modeling respectively.

\section{Flux Tally at a Point or Ring (Type F5)}

This type of tally makes use of what some might call a variance reduction technique, namely, use of the "next event estimator.” For each source particle and each collision event, a deterministic estimate is made of the fluence contribution at the detector point (or ring in an axisymmetric problem). To simplify description of this type 


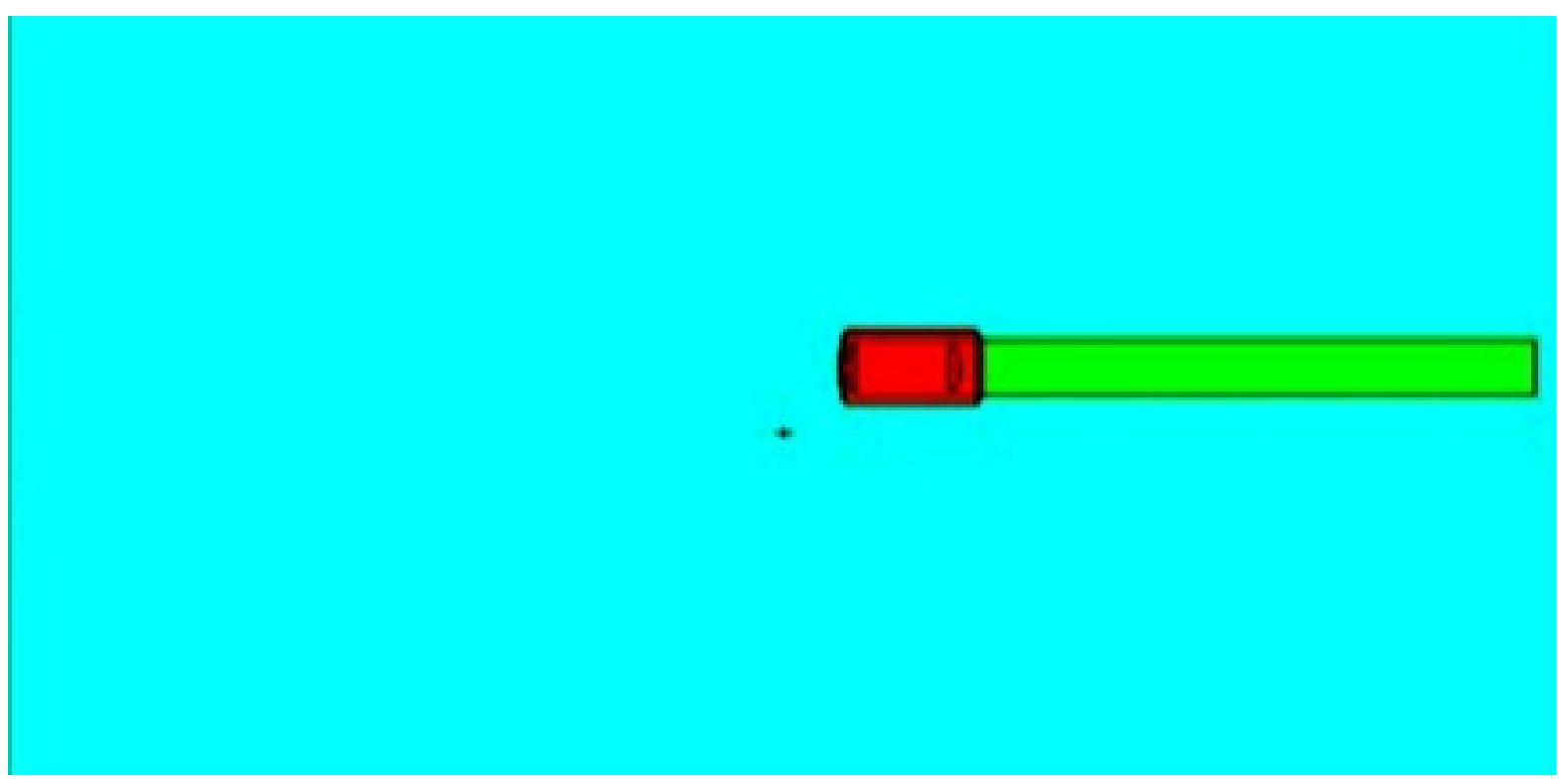

The braided stainless-steel cable was assumed to be 5-mm long and to consist of solid stainless-steel.

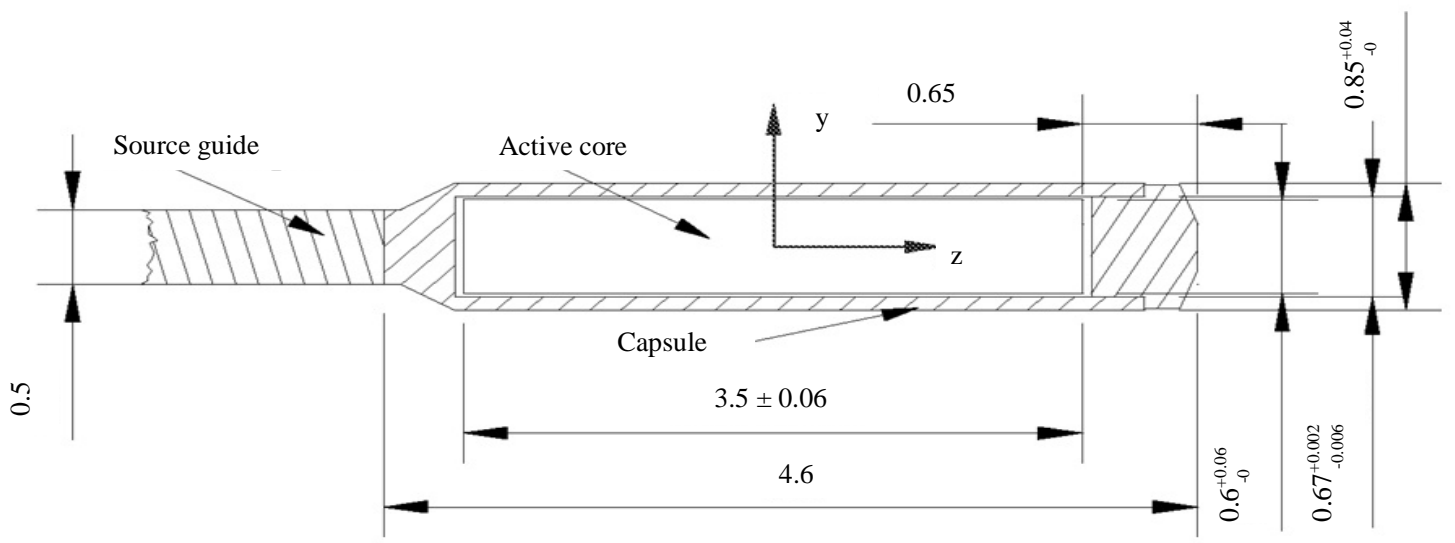

The coordinate system is located at the center of the active part of the source Dimensions are in mm

Figure 3. Schematic design and geometry of brachytherapy flexitron Ir-192 source.

of tally, assume that calculations are being performed in a uniform medium. Suppose a particle of energy $E$ and weight $W$ from an isotropic source is released at distance $r$ from the detector point. Ray theory methodology, as used in the point-kernel method, dictates that the contribution $\delta \Phi$ to the fluence at the detector point is given by:

$$
\delta \Phi=\frac{W}{4 \pi r^{2}} \mathrm{e}^{-\mu E r}
$$

in which $\mu(E)$ is the linear interaction coefficient for the particle of energy $E$. Note that $1 / 4 \pi$ per steradian is the angular distribution of a point isotropic source. Now suppose that a collision takes place at distance $r$ from the detector point and that, to reach the detector point, a scattering angle of $\theta_{s}$ would be required. Here, $E$ is the energy of the particle after the collision and $W$ is its weight. If $\mu\left(E, \theta_{s}\right)$ is the linear interaction coefficient per steradian for scattering at angle $\theta_{s}$, then $\mu\left(E, \theta_{s}\right) / \mu(E)$ is the probability per steradian for scattering at angle $\theta_{s}$. Geometric attenuation remains as $1 / r^{2}$, and the contribution $\delta \Phi$ to the fluence at the detector point is given by 


$$
\delta \Phi=\frac{W \mu\left(E, \theta_{s}\right)}{\mu(E) r^{2}} \mathrm{e}^{-\mu E r}
$$

\section{Dose Rate Measurement}

Locations where dose rate had been estimated in thereby using MCNP5 were first identified and then measured the corresponding distances from the source. Dose rate monitoring was carried out for the selected locations A, $\mathrm{B}, \mathrm{C}, \mathrm{D}, \mathrm{E}$, and F in meter. Measuring doses must be in the range of $0.5 \mu \mathrm{Sv} / \mathrm{h}-7.5 \mu \mathrm{Sv} / \mathrm{h}$. for experimental measurement we used the STEP RDG Detector with Measuring range of $0-2000 \mu \mathrm{Sv} / \mathrm{h}$ and 1.06 correction factor that shown in Figure 4.

\section{Results and Discussion}

Result in Tables 1-5 and Figures 5-9 shows experimental measurement for a Ir-192 HDR source with apparent activity. All of measurement dose rate are under the reference dose rate recommendation of International Atomic Energy Agency.

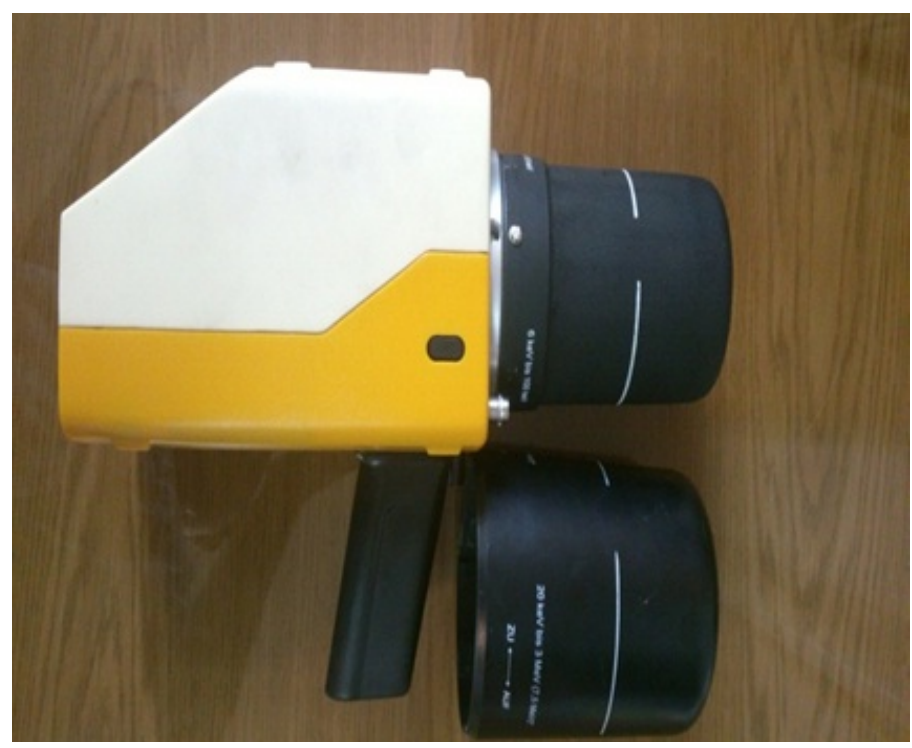

Figure 4. Schematic view of STEP RDG detector.

Table 1. Measurement and comparison between experimental dose rate, referenced dose rate and simulated data for source with $11.5 \mathrm{Ci}$ activity.

\begin{tabular}{|c|c|c|c|c|c|}
\hline \multirow[b]{2}{*}{ Location } & \multicolumn{5}{|c|}{ Table column head } \\
\hline & $\begin{array}{c}\text { Distance from source } \\
\text { (m) }\end{array}$ & $\begin{array}{l}\text { Measured dose rate } \\
(\mu \mathrm{Sv} / \mathrm{h})\end{array}$ & $\begin{array}{c}\text { Reference dose rate } \\
(\mu \mathrm{Sv} / \mathrm{h})\end{array}$ & $\begin{array}{l}\text { Activity } \\
\text { (Ci) }\end{array}$ & $\begin{array}{c}\text { Simulated dose Rate } \\
(\mu S v / h)\end{array}$ \\
\hline Point A & 1.5 & 0.71 & 7.5 & 11.5 & 0.94 \\
\hline Point B & 2 & 0.68 & 7.5 & 11.5 & 0.33 \\
\hline Point C & 3 & 0.66 & 7.5 & 11.5 & 0.166 \\
\hline Point D & 3.5 & 0.5 & 0.5 & 11.5 & 0.32 \\
\hline Point E & 4 & 0.45 & 0.5 & 11.5 & 0.16 \\
\hline Point F & 5 & 0.45 & 7.5 & 11.5 & 0.89 \\
\hline STD & - & 0.121119775 & - & - & 0.354367982 \\
\hline avg & - & 0.575 & - & - & 0.467666667 \\
\hline St.Dev.\% & - & 0.210643088 & - & - & 0.757736241 \\
\hline
\end{tabular}


Table 2. Measurement and comparison between experimental dose rate, reference dose rate and simulation data for source with 6.1 Ci activity.

\begin{tabular}{|c|c|c|c|c|c|}
\hline \multirow[b]{2}{*}{ Location } & \multicolumn{5}{|c|}{ Table column head } \\
\hline & $\begin{array}{c}\text { Distance from source } \\
\text { (m) }\end{array}$ & $\begin{array}{c}\text { Measured dose rate } \\
(\mu \mathrm{Sv} / \mathrm{h})\end{array}$ & $\begin{array}{c}\text { Reference dose rate } \\
(\mu \mathrm{Sv} / \mathrm{h})\end{array}$ & $\begin{array}{l}\text { Activity } \\
\text { (Ci) }\end{array}$ & $\begin{array}{c}\text { Simulated dose Rate } \\
(\mu \mathrm{Sv} / \mathrm{h})\end{array}$ \\
\hline Point A & 1.5 & 0.68 & 7.5 & 6.1 & 0.85 \\
\hline Point B & 2 & 0.66 & 7.5 & 6.1 & 0.33 \\
\hline Point $\mathrm{C}$ & 3 & 0.66 & 7.5 & 6.1 & 0.11 \\
\hline Point D & 3.5 & 0.48 & 0.5 & 6.1 & 0.28 \\
\hline Point $\mathrm{E}$ & 4 & 0.45 & 0.5 & 6.1 & 0.15 \\
\hline Point F & 5 & 0.45 & 7.5 & 6.1 & 0.668 \\
\hline STD & - & 0.113959057 & - & - & 0.296715352 \\
\hline avg & - & 0.563333333 & - & - & 0.398 \\
\hline St.Dev.\% & - & 0.202294184 & - & - & 0.745515959 \\
\hline
\end{tabular}

Table 3. Measurement and comparison between experimental dose rate, reference dose rate and simulation data for source with 5.7 Ci activity.

\begin{tabular}{|c|c|c|c|c|c|}
\hline \multirow[b]{2}{*}{ Location } & \multicolumn{5}{|c|}{ Table column head } \\
\hline & $\begin{array}{l}\text { Distance from source } \\
\text { (m) }\end{array}$ & $\begin{array}{c}\text { Measured dose rate } \\
(\mu \mathrm{Sv} / \mathrm{h})\end{array}$ & $\begin{array}{c}\text { Reference dose rate } \\
(\mu \mathrm{Sv} / \mathrm{h})\end{array}$ & $\begin{array}{l}\text { Activity } \\
\text { (Ci) }\end{array}$ & $\begin{array}{c}\text { Simulated dose Rate } \\
(\mu \mathrm{Sv} / \mathrm{h})\end{array}$ \\
\hline Point A & 1.5 & 0.54 & 7.5 & 5.7 & 0.82 \\
\hline Point B & 2 & 0.54 & 7.5 & 5.7 & 0.32 \\
\hline Point C & 3 & 0.51 & 7.5 & 5.7 & 0.105 \\
\hline Point D & 3.5 & 0.45 & 0.5 & 5.7 & 0.28 \\
\hline Point E & 4 & 0.45 & 0.5 & 5.7 & 0.15 \\
\hline Point $\mathrm{F}$ & 5 & 0.45 & 7.5 & 5.7 & 0.66 \\
\hline STD & - & 0.045166359 & - & - & 0.287618092 \\
\hline avg & - & 0.49 & - & - & 0.389166667 \\
\hline St.Dev.\% & - & 0.092176243 & - & - & 0.739061478 \\
\hline
\end{tabular}

Table 4. Measurement and comparison between experimental dose rate, reference dose rate and simulation data for source with $4.4 \mathrm{Ci}$ activity.

\begin{tabular}{cccccc}
\hline & \multicolumn{5}{c}{ Table column head } \\
Location & $\begin{array}{c}\text { Distance from source } \\
(\mathbf{m})\end{array}$ & $\begin{array}{c}\text { Measured dose rate } \\
(\boldsymbol{\mu S v} / \mathbf{h})\end{array}$ & $\begin{array}{c}\text { Reference dose rate } \\
(\boldsymbol{\mu S v} / \mathbf{h})\end{array}$ & $\begin{array}{c}\text { Activity } \\
(\mathbf{C i})\end{array}$ & $\begin{array}{c}\text { Simulated dose rate } \\
(\boldsymbol{\mu} \boldsymbol{S v} / \mathbf{h})\end{array}$ \\
\hline Point A & 1.5 & 0.61 & 7.5 & 4.4 & 0.802 \\
Point B & 2 & 0.64 & 7.5 & 4.4 & 0.32 \\
Point C & 3 & 0.43 & 7.5 & 4.4 & 0.1 \\
Point D & 3.5 & 0.44 & 0.5 & 4.4 & 0.27 \\
Point E & 4 & 0.42 & 0.5 & 4.4 & 0.15 \\
Point F & 5 & 0.49 & 7.5 & 4.4 & 0.61 \\
STD & - & 0.096488341 & - & - & 0.274901194 \\
avg & - & 0.505 & - & - & 0.375333333 \\
St.Dev.\% & - & 0.191066022 & - & - & 0.732418813 \\
\hline
\end{tabular}


Table 5. Measurement and comparison between experimental dose rate, reference dose rate and simulation data for source with $3.2 \mathrm{Ci}$ activity.

\begin{tabular}{cccccc}
\hline \multirow{2}{*}{ Location } & \multicolumn{5}{c}{ Table column head } \\
\cline { 2 - 6 } & $\begin{array}{c}\text { Distance from } \\
\text { source }(\mathbf{m})\end{array}$ & $\begin{array}{c}\text { Measured dose } \\
\text { rate }(\boldsymbol{\mu S v} / \mathbf{h})\end{array}$ & $\begin{array}{c}\text { Reference dose } \\
\text { rate }(\boldsymbol{\mu S v} / \mathbf{h})\end{array}$ & $\begin{array}{c}\text { Activity } \\
(\mathbf{C i})\end{array}$ & $\begin{array}{c}\text { Simulated dose } \\
\text { rate }(\boldsymbol{\mu S} \mathbf{v} / \mathbf{h})\end{array}$ \\
\hline Point A & 1.5 & 0.68 & 7.5 & 3.2 & 0.79 \\
Point B & 2 & 0.66 & 7.5 & 3.2 & 0.3 \\
Point C & 3 & 0.66 & 7.5 & 3.2 & 0.097 \\
Point D & 3.5 & 0.51 & 0.5 & 3.2 & 0.267 \\
Point E & 4 & 0.45 & 0.5 & 3.2 & 0.12 \\
Point F & 5 & 0.45 & 7.5 & 3.2 & 0.58 \\
STD & - & 0.110166541 & - & - & 0.272877995 \\
avg & - & 0.568333333 & - & - & 0.359 \\
St.Dev.\% & - & 0.19384142 & - & - & 0.760105835 \\
\hline
\end{tabular}

Source with 11.5 Ci Activity

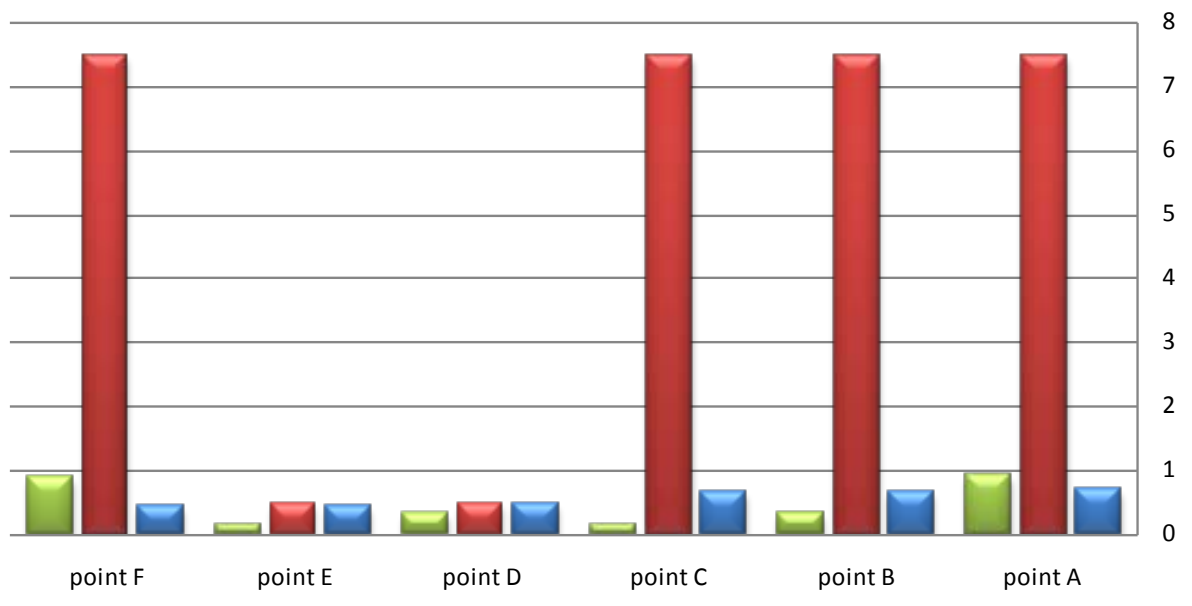

Experimental Dose rate $(\mu \mathrm{Sv} / \mathrm{h}) \quad \square$ Refrence Dose rate $(\mu \mathrm{Sv} / \mathrm{h}) \square$ Simulated Dose Rate $(\mu \mathrm{Sv} / \mathrm{h})$

Figure 5. Schematic view of measured dose rate, reference dose rate and simulated dose rate for each point for the source with $11.5 \mathrm{Ci}$ activity.

Source with 6.1 Ci Activity

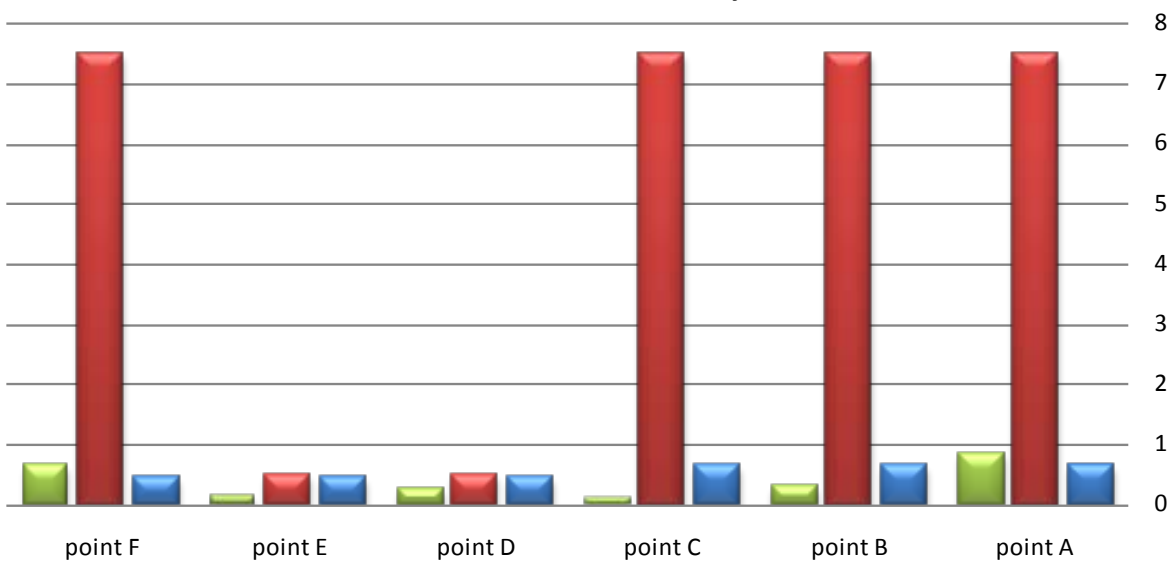

$\square$ Experimental Dose rate $(\mu \mathrm{Sv} / \mathrm{h}) \square \operatorname{Refrence}$ Dose rate $(\mu \mathrm{Sv} / \mathrm{h}) \square$ Simulated Dose Rate $(\mu \mathrm{Sv} / \mathrm{h})$

Figure 6. Schematic view of measured dose rate, reference dose rate and simulated dose rate for each point for the source with $6.1 \mathrm{Ci}$ activity. 
Source with 5.7 Ci Activity

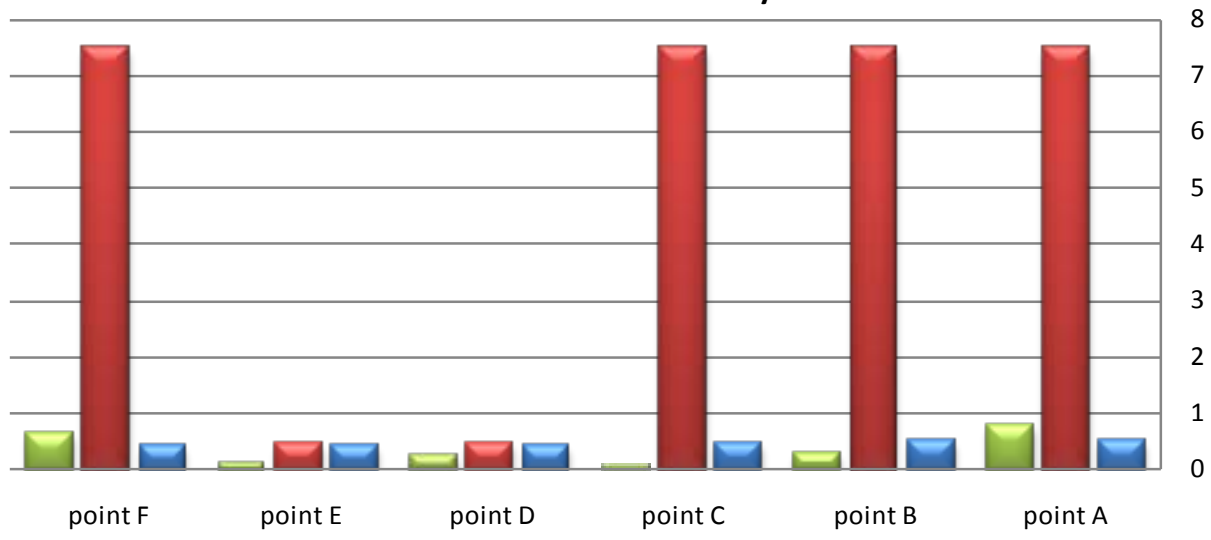

$\square$ Experimental Dose rate $(\mu \mathrm{Sv} / \mathrm{h}) \boxminus$ Refrence Dose rate $(\mu \mathrm{Sv} / \mathrm{h}) \square$ Simulated Dose Rate $(\mu \mathrm{Sv} / \mathrm{h})$

Figure 7. Schematic view of measured dose rate, reference dose rate and simulated dose rate for each point for the source with $5.7 \mathrm{Ci}$ activity.

Source with 4.4 Ci Activity

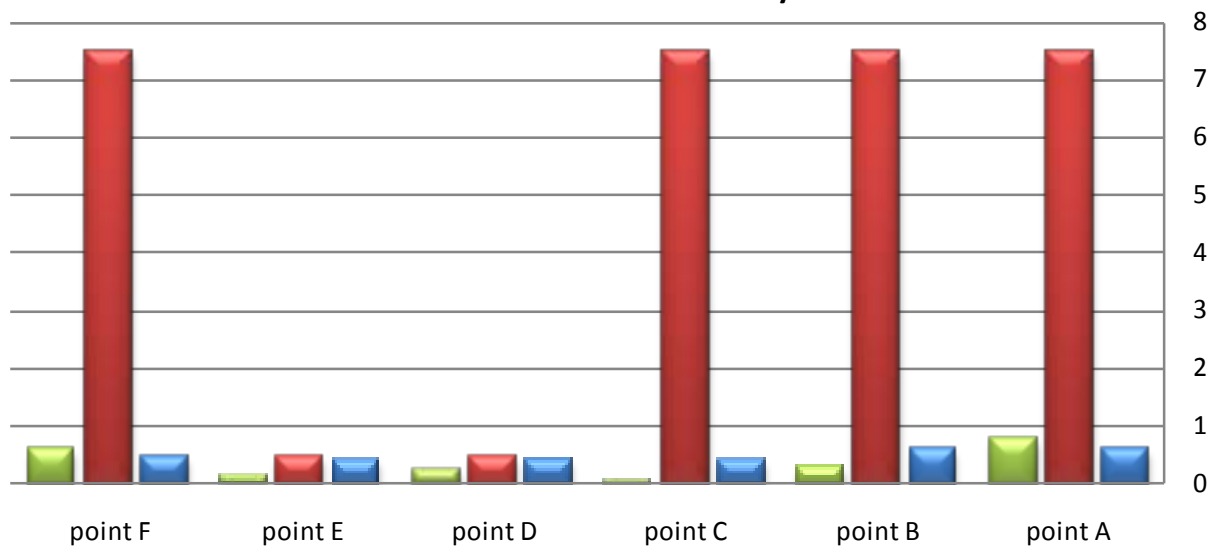

$\square$ Experimental Dose rate $(\mu \mathrm{Sv} / \mathrm{h}) \boxminus$ Refrence Dose rate $(\mu \mathrm{Sv} / \mathrm{h}) \square$ Simulated Dose Rate $(\mu \mathrm{Sv} / \mathrm{h})$

Figure 8. Schematic view of measured dose rate, reference dose rate and simulated dose rate for each point for the source with $4.4 \mathrm{Ci}$ activity.

Source with 3.2 Ci Activity

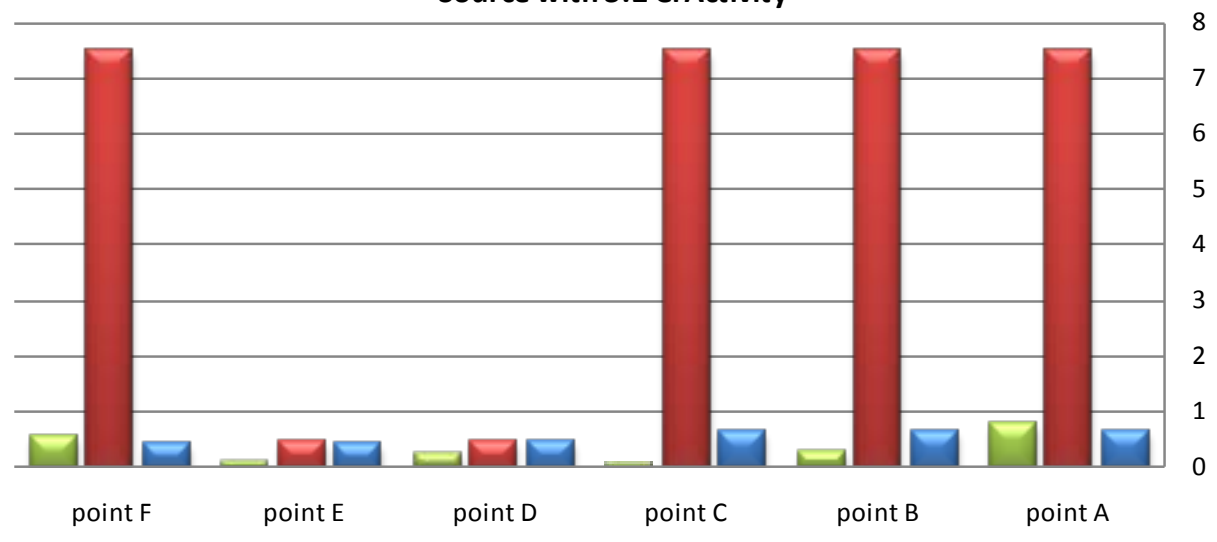

$\square$ Experimental Dose rate $(\mu S v / h) \square$ Refrence Dose rate $(\mu S v / h) \square$ Simulated Dose Rate $(\mu S v / h)$

Figure 9. Schematic view of measured dose rate, reference dose rate and simulated dose rate for each point for the source with $3.2 \mathrm{Ci}$ activity. 


\section{Conclusion}

The measured dose rates at the selected locations representing supervised areas are all below the recommended values for public areas of $0.5 \mu \mathrm{Sv} / \mathrm{h}$. The controlled areas are also below the value recommended for controlled areas of $7.5 \mu \mathrm{Sv} / \mathrm{h}$. This implies that the biological shielding design of the facility is adequate to attenuate the gamma radiations from the brachytherapy sources used for treatment and hence the general public and staff are adequately protected for the existing HDR Ir-192 brachytherapy system. But unfortunately we saw an over estimate in calculation of room shielding design.

\section{References}

[1] Cashwell, E.D. and Everett, C.J. (1959) A Practical Manual on the Monte Carlo Method for Random Walk Problems. Pergamon Press, Oxford.

[2] https://mcnpx.lanl.gov/opendocs/misc/FeaturesList

[3] Los Alamos National Laboratory, New Mexico, United States. https://mcnp.lanl.gov

[4] L.A.N. Laboratory (2000) Monte Carlo N-Particle Transport Code System.

[5] Alain Gerbaulet RP, Harm Meertens, Erik Van Limbergen (2001) The GEC ESTRO Handbook of Brachytherapy. ESTRO, Brussels.

[6] Arthur B. Chilton, Richard E. (1984) Principle of Radiation Shielding. Prentice Hall, Kanas.

[7] Joslin, A. and Hall, E.J. (2001) Principle and Practice of Brachytherapy Using after Loading Systems. Joanna Koster, London.

[8] (1996) International Basic Safety Standards for Protection against Ionizing Radiation and for the Safety of Radiation Sources. IAEAsafety Series, Vienna.

[9] (2006) Radiation Oncology Physics: A Handbook for Teachers and Students. IAEA, Vienna.

[10] (1997) The Design of Radiotherapy Treatment Room Facilities. IPEM, York.

[11] (2006) Radiation Protection in the Design of Radiotherapy Facilities, Safety Reports Series No. 47. International Atomic Energy Agency, Vienna.

[12] Elert, G. (2008) Density of Wood. Shirley Lam.

[13] Schwarz, R.A.S.A.L. and Carter, L.L. (2008) MCNP/MCNPX Visual Editor Computer Code Manual.

[14] Team, X.-M.C. (2008) A General Monte Carlo N-Particle Transport Code. Version 5, Los Alamos National Laboratory, New Mexico, United States. 